\title{
Scaling geological fracture network from a micro to a macro scale
}

\author{
Rouhollah Basirat, Kamran Goshtasbi*, Morteza Ahmadi \\ Faculty of Engineering, Tarbiat Modares University, Tehran, Iran \\ goshtasb@modares.ac.ir
}

\begin{abstract}
Characterizing fracture systems at various scales, modeling fracture distributions, and clarifying scale relations that correlate total fracture systems are of paramount importance in geology, mining, civil engineering, and petroleum engineering. In this paper, the conditions of fracture network geometry are investigated in a field scale (about $100 \mathrm{~m}$ ) and a core sample scale (several centimeters). To achieve this purpose, field surveys and coring of rock outcrops were performed in the Asmari Formation of Iran. Fractures were manually sampled from rock outcrops on the field scale while micro-fractures were surveyed using CT-scan images of core samples on a small scale. To compare the fracture network geometry, two perspectives of fractal dimensions and orientation of fractures were used. The results showed that the fractal dimension has the same value in both field and core scales and the orientation of the fractures is similar in both scales. Therefore, it can be claimed that in the Asmari Formation of Iran the structure of the fracture network is similar in two studied scales.
\end{abstract}

KEYwORDS. Asmari Formation; CT-scan; Fractal Dimension; Fracture System; Scaling

\section{open Access}

Citation: Basirat, R., Goshtasbi, K., Ahmadi, M., Scaling geological fracture network from a micro to a macro scale, Frattura ed Integrità Strutturale, 51 (2020) 71-80.

Received: 16.09 .2019

Accepted: 14.10 .2019

Published: 01.01.2020

Copyright: (C) 2020 This is an open access article under the terms of the CC-BY 4.0, which permits unrestricted use, distribution, and reproduction in any medium, provided the original author and source are credited.

\section{INTRODUCTION}

$\mathrm{R}$ ock fractures are observed at various scales ranging from several micrometers to hundreds of kilometers [1, 2] and often exhibit high scale invariance and self-similarity [3-6]. Therefore, recognizing the scaling behavior of natural fracture systems opens the possibility for characterization of macro-scale properties of fractured rock/medium from a relatively smaller sampled model [7].

Fractal concepts can be applied to these issues in a variety of ways. A fractal distribution is the only statistical distribution that is scale-invariant [8]. One of the most remarkable features of the concept of fractal introduced by Mandelbrot [9] is the description and understanding of self-similarities. Self-similarity refers to the well-known observation that the Earth's morphology looks the same at a variety of scales. This feature-is used in numerous investigations including breakage and fragmentation [10], the interaction of fracture growth processes correlations from macro-scale frameworks to micro-scale fabrics [1,3], tectonic interpretation of the connectivity of a multiscale fracture system [11], fault and fractures patterns [1215], modeling porous media by scaling mass, pore space, and pore surface [16], the terrain fault distribution [17], and clustering of earthquakes $[18,19]$. 
In the present study, the geometry of Fracture Network (FN) is studied in two limestone media in the Asmari Formation of Iran. Then, the geometric state of the FNs is compared with each other in a field scale (about $100 \mathrm{~m}^{2}$ ) and a small scale (from core specimens with a diameter of 9 and $5.4 \mathrm{~cm}$ ). In this way, the question of "does the fracture network have a similar geometry at different scales?" is answered for a fractured geological media using two tools of Fractal Dimension and Stereonet Diagram.

\section{GEOLOGY AND SAMPLING}

\section{Geology of the study area}

he main feature of the Asmari Formation is the presence of multiple fractures. The importance of these fractures is mainly emphasized in two areas of civil engineering for the analysis of the stability of the structure and in the oil fields of the Zagros region. Fractures play a major role in the migration and production of hydrocarbon reservoirs. Iran's carbonate formations have a global reputation in this regard.

The Asmari Formation is one of the prominent constituents of the Zagros sedimentary-tectonics province. This formation is extensively developed in Zagros and is the youngest reservoir of hydrocarbons in Zagros. The formation is named after its type section in the Asmari Mountains, southeast of Masjed Soleyman. Asmari Formation is comprised of cream to brown colored limestone with feature form and numerous joints. The age of this formation is detected using its Oligo-Miocene fossils (1-2 million years ago) from a biostratigraphy point of view, Asmari is divided into three lower, middle, and upper Asmari units. However, these units are not seen everywhere.

In the central Lorestan, this Formation is associated with the Shahbazan Carbonate Formation and in the inner Fars, it is accompanied by the Jahrom Formation parallel to a para-conformity. The Asmari Formation is covered with Gachsaran anhydrite formation in the everywhere of Zagros.

In this paper, Asmari Formation Limestone was used to investigate the geometry of FN in two different scales. To achieve this aim, the geometry of fractures was investigated in two close areas. These two regions are located in the Lorestan province of Iran. Fig. 1 shows the geological map and the location of the studied area.

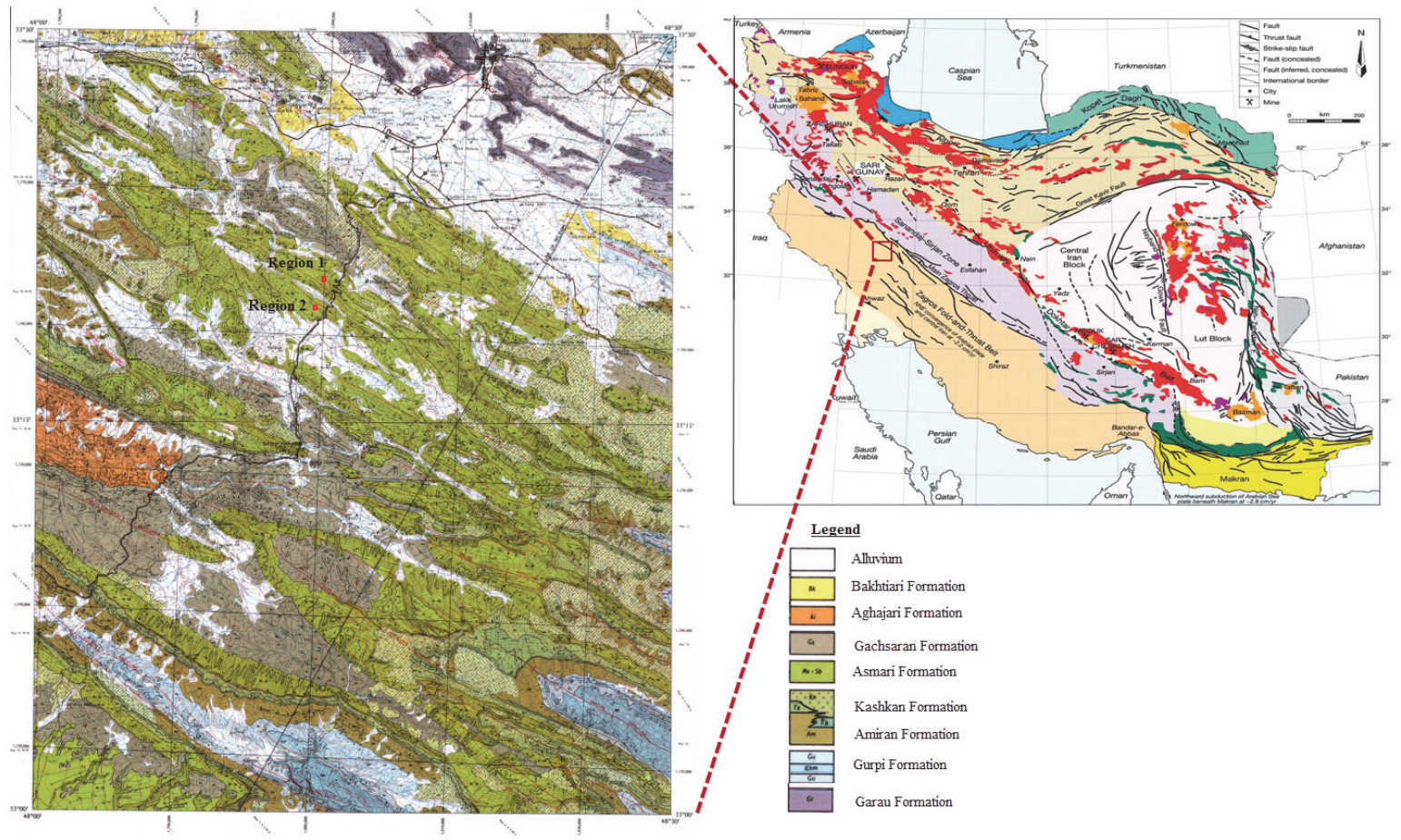

Figure 1: The geological map and the location of the two study areas

\section{Sections and core sampling}

Two limestone outcrops were selected for determining the joint sets as well as core sampling. Fig. 2 illustrates the outcrops of two studied regions. Core sampling with diameters of 54 and $90 \mathrm{~mm}$ was done from two regions. It is of note that the 
rock samples and the field rock mass were from the same site. Six samples were collected from each region (12 samples in total). Tab. 1 shows the diameter and height of the core samples. Then, fractures in the core samples were extracted using a CT-Scan device (Model: Bright Speed) (Fig. 3). Fig. 4 presents the core samples and CT-scan records for two studied regions. The output of the CT-scan device is sliced with a spacing of $0.1 \mathrm{~mm}$ in three perpendicular directions.

\begin{tabular}{ccc|ccc}
\hline \multicolumn{3}{c|}{ Region 1 (Fig. 1.a) } & \multicolumn{3}{c}{ Region 2 (Fig. 1.b) } \\
No. & Diameter (cm) & Height (cm) & No. & Diameter (cm) & Height (cm) \\
A1 & 9 & 22.1 & B1 & 5.4 & 13.9 \\
A2 & 9 & 23 & B2 & 9 & 14.1 \\
A3 & 9 & 19.1 & B3 & 9 & 19.6 \\
A4 & 5.4 & 22.2 & B4 & 9 & 19.3 \\
A5 & 5.4 & 24.5 & B5 & 5.4 & 25.8 \\
A6 & 5.4 & 17.3 & B6 & 5.4 & 19.9 \\
\hline
\end{tabular}

Table 1: The size of core samples for two study regions

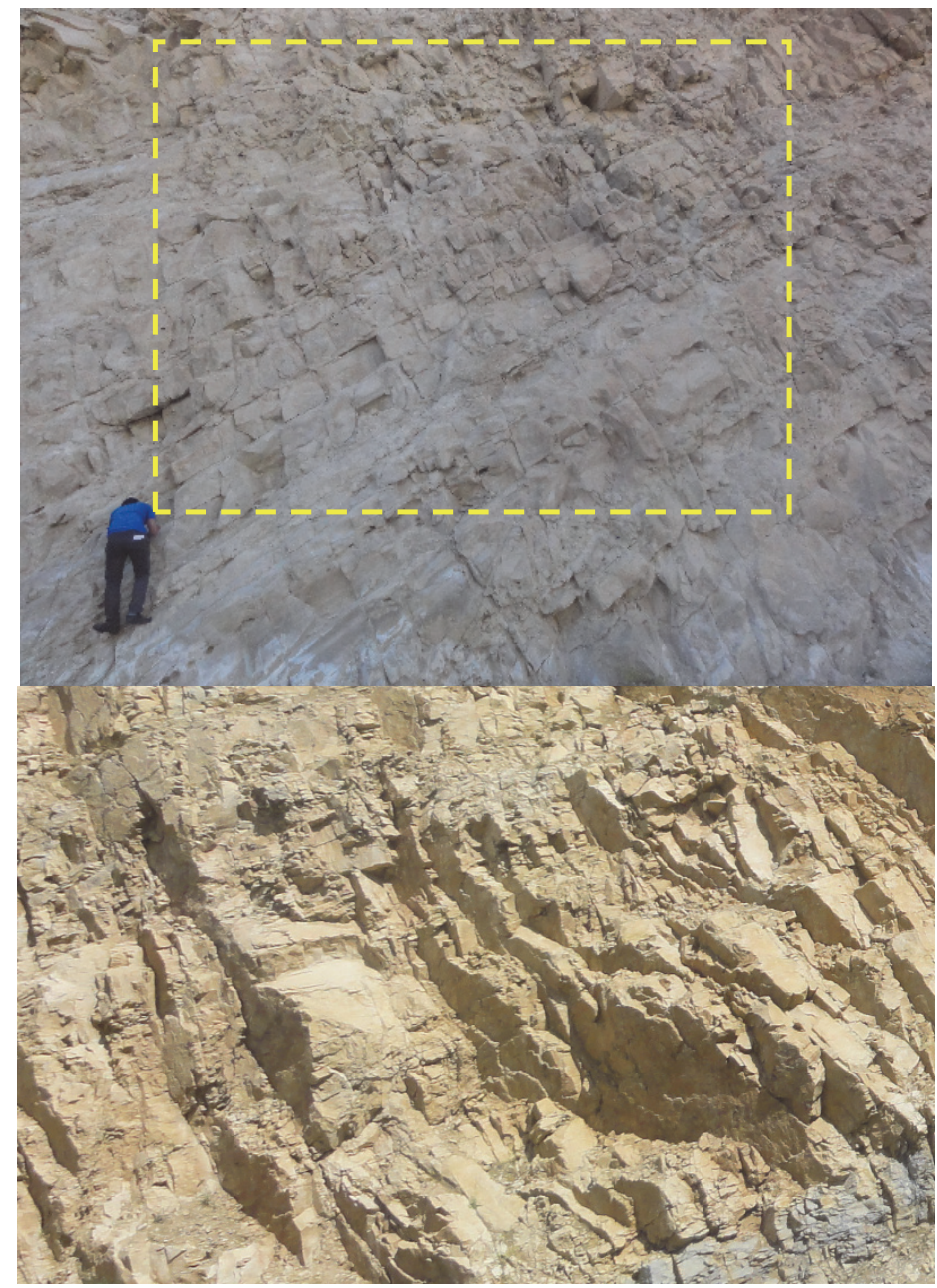

Figure 2: Two examples of limestone rock mass outcrops with FN 

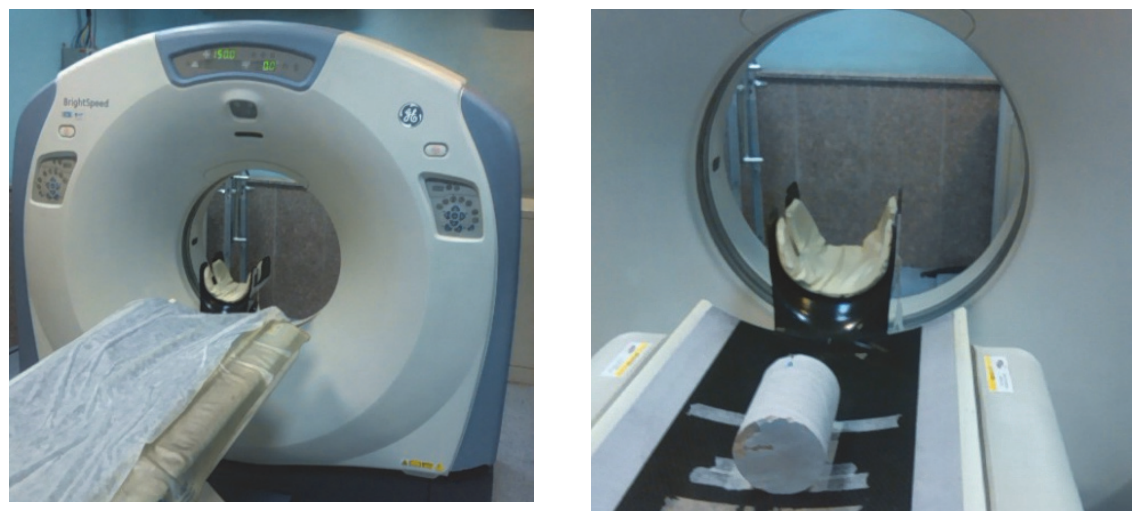

Figure 3: CT-Scan devise

Region 1

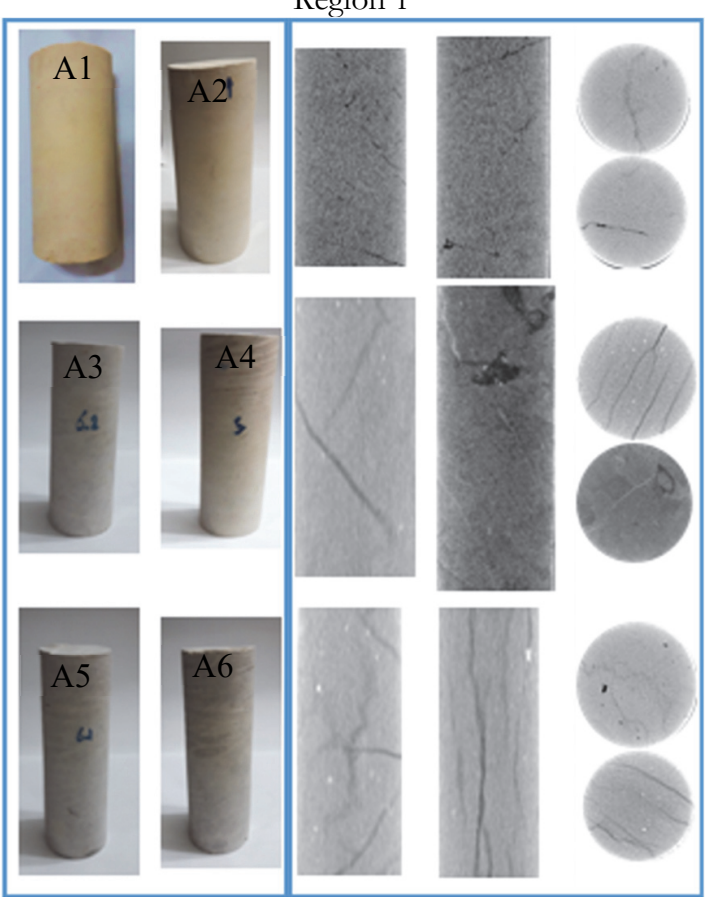

Region 2

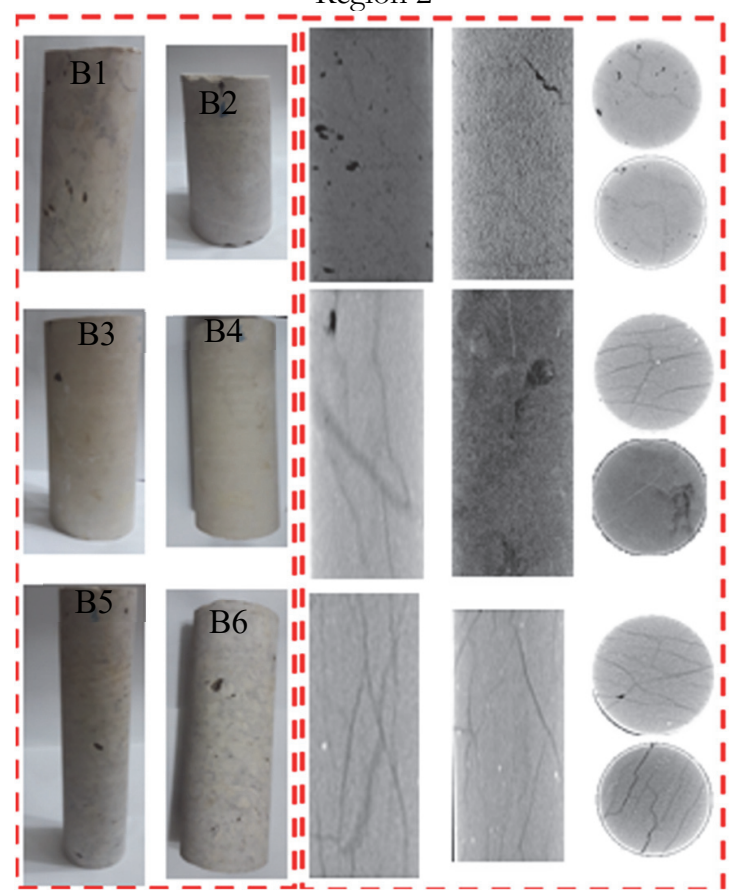

Figure 4: CT-Scan devise, core samples, and digital images output of the CT-scan

\section{METHODOLOGY}

\section{Calculation of Fractal Dimension (D) using Digital Image Processing}

7 ractal dimension is a very important parameter in the rock fracture system characterization since it describes how 1 fractures are distributed in the outcrop. The spatial scaling feature can be characterized by the fractal dimension (D).

The geometry of fractals is described by power-law distribution and the potential $\mathrm{D}$ is represented by [20]:

$$
N_{i}=C / r_{i}^{D}
$$

where $N_{i}$ is the number of objects (here is the number of fractures) with a characteristic linear dimension $r$, $D$ is the fractal dimension, and $C$ is a constant of proportionality.

Fracture patterns are classical examples of the successful application of Box Counting on the micro-scale to mega-scale and to various materials [21-24]. In this research, a MATLAB code was developed to provide a good and easily manageable estimation of the fractal dimension of FN based on image processing. Digital face mapping is a practical tool to characterize 
rock masses and significantly reduce the time required in the field and avoid exposure to potentially unsafe conditions. The steps for automatic calculation of $\mathrm{D}$ are described as follows.

(1) Converting the color image of the rock mass to a gray-scale

The established edge and line detection methods available in the MATLAB image processing toolbox are designed for digital photographs. Therefore, the matrix must be converted to grey-scale intensity values.

(2) Preprocessing the digital image

To demonstrate the fractures, the image needs to be sharpened using a common high pass filter. By sharpening the images, the contrast between bright and dark regions are enhanced [25]. Therefore, we filtered the original image by a high-pass filter and extract the high-frequency components. Then, a scaled version of the high-pass filter output was added to the original image. In this paper, histogram equalization was employed to adjust image intensities in order to enhance the images' contrast [26].

(3) Edge detection

Points in the image where brightness changes rapidly are often called "edges" or "edge points". An edge is a set of the connected pixels that lie on the boundary between two regions. The edge detection is the most common approach for detecting noticeable discontinuities in the intensity range [25]. Change in the intensity values can be detected by estimating the first derivative of the image intensity. The edge detection algorithms usually are followed by linking procedures to assemble edge pixels into meaningful pixels. In this research, we applied the Hough transform-based line detecting using the Canny algorithm, which is the most popular edge detector. This detector is based on the first derivative of the image intensity values versus distance [27].
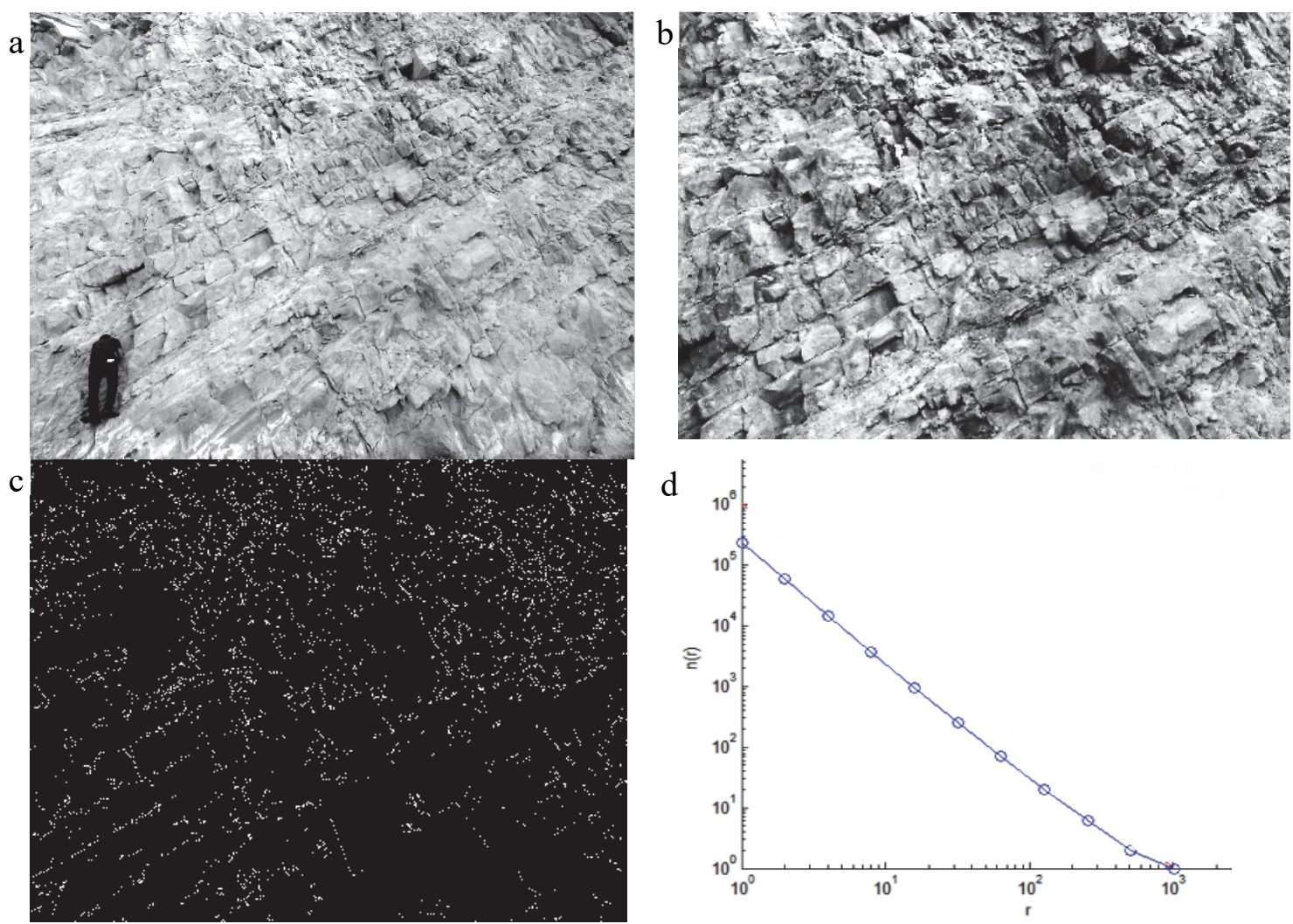

Figure 5: Calculation of fractal dimension using image processing technique: a) converting the color image to gray-scale, b) preprocessing the digital image using Histogram equalization method, c) edge detection using the Canny algorithm, and d) calculation fractal dimension from the log-log diagram

(4) Calculation of fractal dimension

The fractal dimension is calculated based on edges detected in the previous steps. In this paper, we used the method proposed by Kulatilake et al. [28] for calculating the fractal dimension. The investigated curve or the joint trace data area is covered by a square box (two-dimensional) in the initial step. In the next iteration, the box size is decreased by a certain factor, termed as the reduction factor, S. For each box network considered in the calculations, the computer program creates 
a window of the respective box size. This window is then moved from one place to another in an imaginary network of boxes over the data area. At every stop, the program verifies whether there is any trace of the investigated feature falling in this box. The number of boxes needed to completely cover the feature is counted and plotted in a log-log plot of the number of boxes $(\mathrm{N})$ needed to cover the feature versus box size $(\mathrm{Y})$. Each iteration gives a point in this plot. Using the reduction factor, a number of iterations are applied until the smallest box size is close to the smallest feature size of the curve. The slope of the line equals the negative estimated fractal dimension of the shape. The fractal dimension is estimated starting from the second iteration until the last iteration [28].

The further details of these steps are explained in Refs. [26, 29, 30]. This method (i.e., calculating the fractal dimension by digital image processing) also was verified through manual and different methods by Basirat et al. [31]. This process was applied in a macro-scale (outcrop photos) image and a micro-scale (CT-scan) image. Fig. 5 presents the mentioned steps for an outcrop photo.

\section{The orientation of fractures}

The orientation is a fundamental characteristic of fracture arrays. This parameter is characterized by the dip and dip direction. Dip angle is the dihedral angle the fracture plane makes with the horizontal plane that gives the steepest angle of descent of a discontinuity plane to a horizontal plane. This angle is measured in the vertical plane perpendicular to the strike. Dip direction is the azimuth of the horizontal trace of the dip line, measured clockwise from the north.

The orientation of fractures for both scales was traditionally measured by a compass using the field (in the outcrop) and CT-scan images. To determine the position of the micro-fracture network, one needs to correctly consider the azimuth of the core samples.
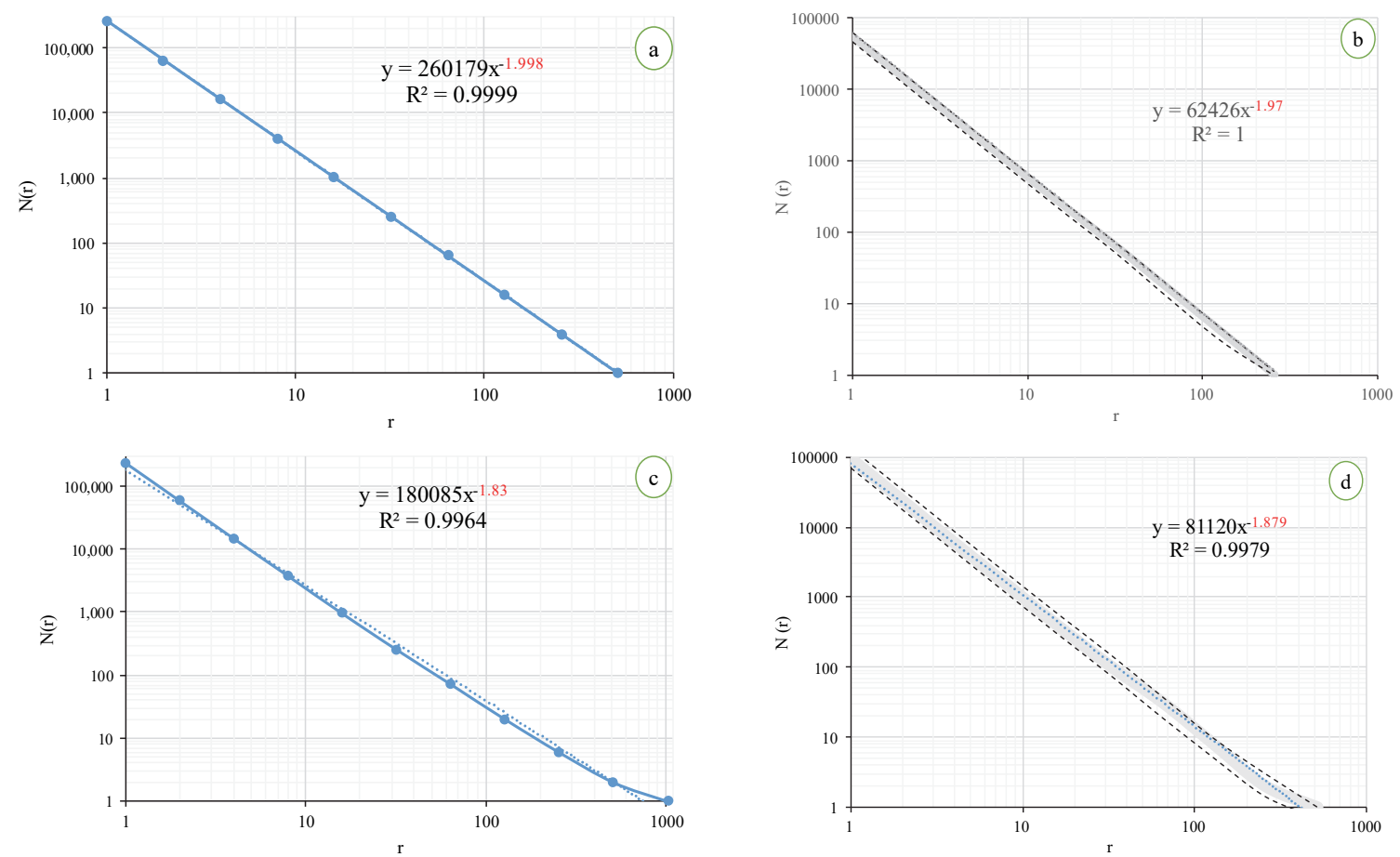

Figure 6: The log-log size-frequency of fracture in two studied areas for two scales; a) the results of field surveying for Region 1, b) the results of CT-scan of core samples for region 1, c) field surveying for region 2, d) CT-scan of core samples for region 2

\section{DISCUSSION AND RESULT SURVEYING}

7 he results of the steps outlined in sections "calculation of fractal dimension using digital image processing" and "the orientation of fractures" are shown in Figs. 6 and 7, respectively. Fig. 6 represents a log-log diagram of the sizefrequency of fractures for the two studied areas at two field and samples scales. In this Figure, $r$ and $N(r)$ is pixel size and the number of pixels, which are known as a fracture (in every step). Results of all CT-scan images after determining their fractal dimension are denoted in Fig. 6 (right side). Three CT-Scan slices of every core samples were considered for 
calculating fractal dimension (totally 36 slices). When determining the fractal dimension of micro-fractures from CT-scan images, we should select only the sections that have the same azimuth (direction) with the images of the field observations. According to Fig. 6, the fractal dimension of the FN is close to each other in two scales for both regions. Therefore, the same changing ratio happens between numbers of fractures and scales of the fractures. In other words, the same patterns occur at two scales.

a

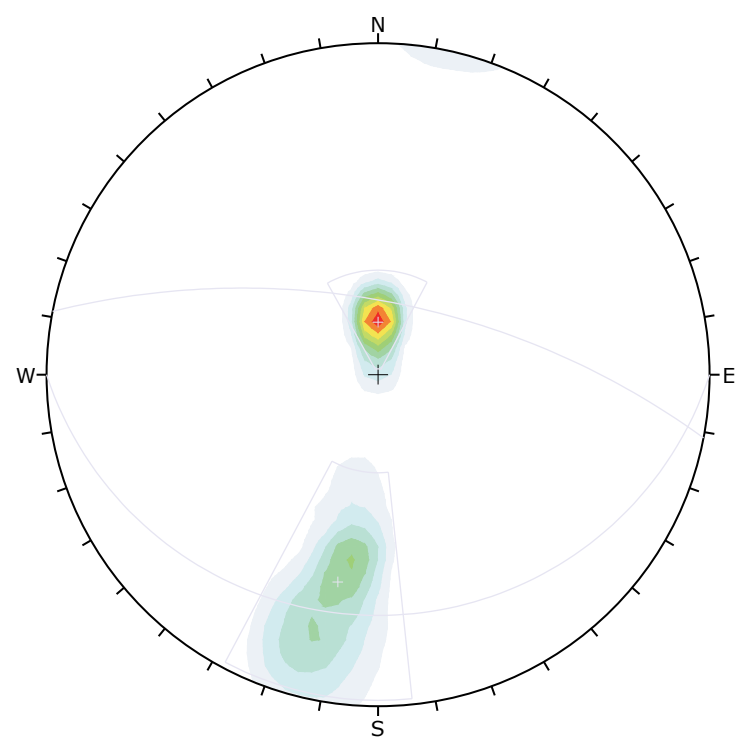

c

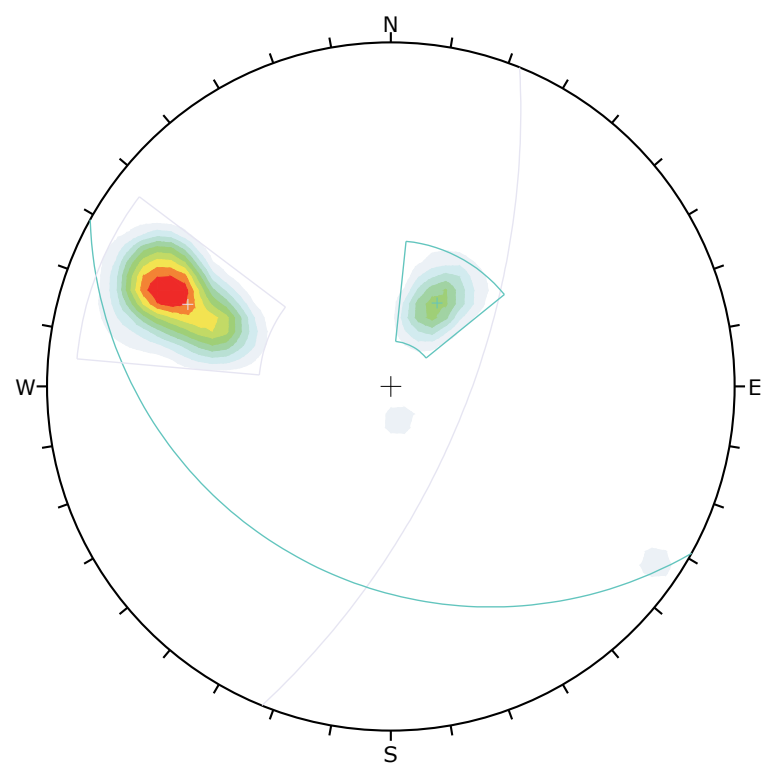

$\mathrm{b}$

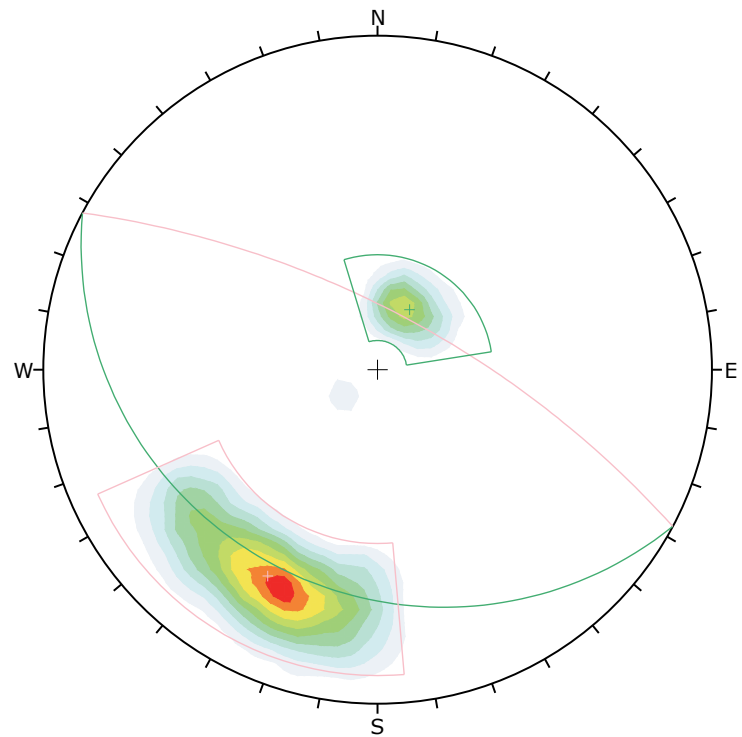

d

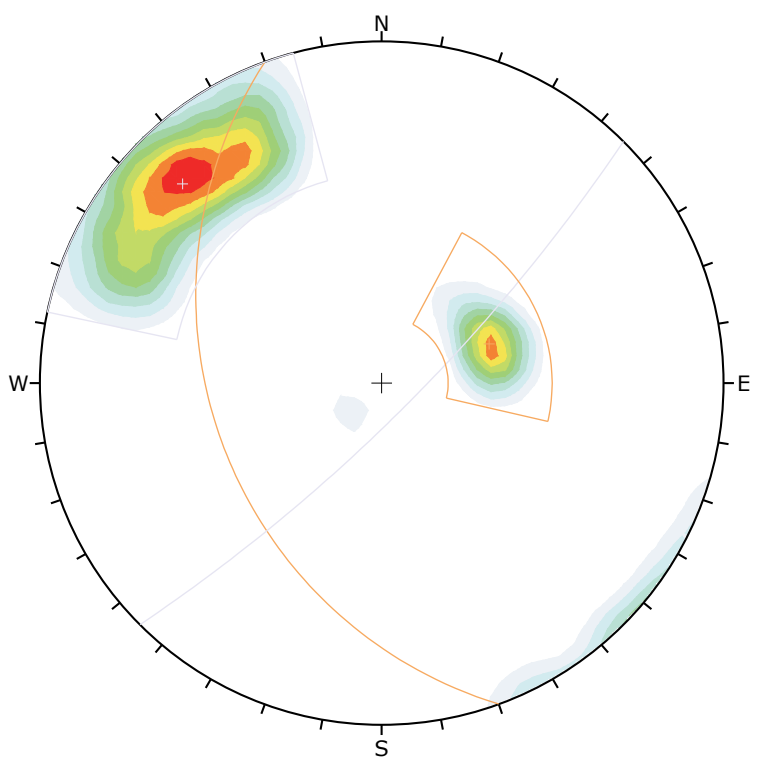

Figure 7: The spatial position of the fracture using contour plot of pole vectors in two studied areas for two scales; a) the results of field surveying for Region 1, b) the results of CT-scan of core samples for region 1, c) field surveying results for region 2, d the results of core samples for region 2

Fig. 7 presents the contour plots of pole vectors of all fractures in two studied areas using the CT-scans and field data projected on an equal angle stereonet. The pole vector is the normal vector of a fracture plane. About 100 joints were determined manually from each outcrop. The number of micro-fractures obtained from CT-scan images for regions 1 and 2 were 33 and 43, respectively. Fig. 8 shows the number of micro-fractures of core samples for two studied regions.

Since the number of micro-fracture was not equal in all of the CT-scan images of core samples from the same region (in some rock cores, it was less than 3 micro-fractures, but in some others it was more than 7 micro-fractures), all microfractures from the same region were projected in the stereonet plot of CT-scan of core samples. Tab. 2 illustrates the dip and dip direction for two studied areas in two field and core sample scales. The quantitative difference between two scales 
also presented in this table. According to Fig. 7, the FN is similar for the two scales. There are two main types of joint set in both scales. Although the scattering of micro-fractures is more than the fractures collected at the field scale, the dip and dip direction are close to each other. Therefore, it can be stated that the geometry of the FN in Asmari Formation of Iran is similar at the studied scales.
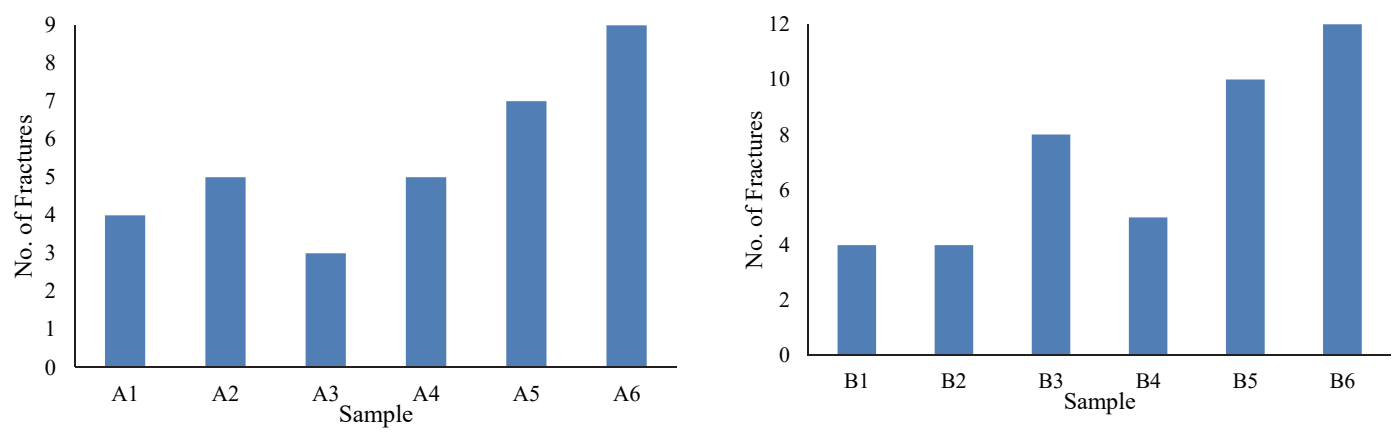

Figure 8: The number of micro-fractures of core samples for region 1 (the left diagram) and region 2 (the right diagram)

\begin{tabular}{cccc}
\hline Scale & Joint Set & Region 1 & Region 2 \\
Field scale & First joint set & $65 / 013$ & $31 / 209$ \\
& Second joint set & $18 / 180$ & $65 / 112$ \\
\hline \multirow{2}{*}{ Core Sample scale } & First joint set & $70 / 028$ & $37 / 249$ \\
& Second joint set & $23 / 208$ & $79 / 135$ \\
\hline $\begin{array}{l}\text { Difference (dip/dip } \\
\text { direction) in degree }\end{array}$ & First joint set & $5 / 015$ & $6 / 040$ \\
\hline
\end{tabular}

Table 2: Dip/Dip direction for two studied areas in two different scales

\section{CONCLUSION}

$\mathrm{I}$ $\mathrm{n}$ this paper, the conditions of the fracture network geometry of Asmari Formation were surveyed on a field scale and a core sample scale. Fractures were manually sampled from rocky outcrops on the field scale while micro-fractures were investigated using CT-scan images of core samples. In order to compare the fracture geometry, two related concepts of fractured media were used; i.e., fractal dimensions and orientation of fractures. The results indicated that the fractal dimension has the same value in both scales and the orientation of the fractures also is similar in both scales for Asmari Formation of Iran. Hence, it can be concluded that the fracture network has a similar geometry at different scales for the Asmari Formation of Iran.

\section{ACKNOWLEDGMENT}

uthors would like to sincerely thank Dr. Zhou, Dr. Zhao, and Dr. Lee for answering our emails and giving insightful comments. Special thanks also go to Mr. Khannazer and Mr. Mirkazemian as two Iranian expert geologists for giving valuable notes about Asmari formation of Iran. 


\section{REFERENCES}

[1] Bonnet, E., Bour, O. Odling, N. E. Davy, P. Main, I. Cowie, P. and Berkowitz, B., (2001). Scaling of fracture systems in geological media, Rev. Geophys., 39(3), pp. 347-383, DOI: 10.1029/1999RG000074.

[2] Davy, P. and Bour, O. (2006). Flow in multiscale fractal fracture networks. Geological Society London Spatial Publications, DOI: 10.1144/GSL.SP.2006.261.01.03.

[3] Barton, C. C., and La Pointe, P. R., (1995). Fractals in the Earth Sciences, Plenum Press, New York.

[4] Odling, N. E., (1992). Network properties of a two-dimensional natural fracture pattern, Pure Appl. Geophys., 138(1), pp. 95-114, DOI: 10.1007/BF00876716.

[5] Berkowitz, B., Bour, O., Davy, P., and Odling, N. (2000). Scaling of fracture connectivity in geological formations, Geophys. Res. Lett., 27(14), pp. 2061-2064, DOI: 10.1029/1999GL011241.

[6] Bour, O., Davy, P. and Dacel, C., (2002). A statistical scaling model for fracture network geometry, with validation on a multiscale mapping of a joint network (Hornelen Basin, Norway), J. Geophys. Res., 107(B6), 2113, DOI: 10.1029/2001JB000176.

[7] Zimmerman, R. W., and Main, I., (2004). Hydromechanical behavior of fractured rocks, in Mechanics of Fluid-Saturated Rocks, edited by Y. Gueguen and M. Bouteca, pp. 363-421, Elsevier, London.

[8] Turcotte D.L., Huang J. (1995). Fractal Distributions in Geology, Scale Invariance, and Deterministic Chaos. In: Barton C.C., La Pointe P.R. (eds) Fractals in the Earth Sciences. Springer, Boston, MA, DOI: 10.1007/978-1-4899-1397-5_1.

[9] Mandelbrot, B. B., (1997). Fractal: Form, Chance and Dimension: Geometry of Nature, W H. Freeman, San Francisco.

[10] Allègre, C. J., Lemouel, J. L. and Provost, A. (1982). Scaling rules in rock fracture and possible applications for earthquake prediction. Nature, 297, pp. 47-49, DOI: 10.1038/297047a0.

[11] Lei, Q., and Wang, X., (2016). Tectonic interpretation of the connectivity of a multiscale fracture system in limestone, Geophys. Res. Lett., 43, pp. 1551-1558, DOI: 10.1002/2015GL067277.

[12] Walsh, J.J. and Watterson, J. (1992). Populations of faults and fault displacements and their effects on estimates of faultrelated regional extension, Journal of Structural Geology, 14 (6), 701-712, DOI: 10.1016/0191-8141(92)90127-I.

[13] Soliva, R., and Schultz, R. A. (2008). Distributed and localized faulting inextensional settings: Insight from the North Ethiopian Rift - Afartransition area, Tectonics, 27, TC2003, DOI:10.1029/2007TC002148.

[14] Davy, P., Le Goc, R., Darcel, C., Bour, O., de Dreuzy, J. R., and Munier, R. (2010). A likely universal model of fracture scaling and its consequence for crustal hydromechanics, J. Geophys. Res., 115, B10411, DOI: 10.1029/2009JB007043.

[15] Lei, Q., Latham, J. P. Tsang, C.F. Xiang, J. and Lang, P., (2015). A new approach to upscaling fracture network models while preserving geostatistical and geomechanical characteristics, J. Geophys. Res. Solid Earth, 120, pp. 4784-4807, DOI: 10.1002/2014JB011736.

[16] Giménez, D., Perfect, E., Rawls, W.J., Pachepsky, Y., (1997). Fractal models for predicting soil hydraulic properties: a review, Engineering Geology, 48, 3-4, pp. 161-183, DOI: 10.1016/S0013-7952(97)00038-0.

[17] Zhao, Y., Feng, Z., Liang, W., Yang, D., Hu, Y., Kang, T. (2009). Investigation of fractal distribution law for the trace number of random and grouped fractures in a geological mass, Engineering Geology, 109, 3-4, pp. 224-229, DOI: $10.1016 /$ j.enggeo.2009.08.002

[18] Smalley, R.F., Chatellain, L.L., Turcotte, D.L., Prevot, R.A., (1987). Fractal approach to the clustering of earthquakes: applications to the seismicity of the New-Hebrides. Bulletin of the Seismological Society of America 77.

[19] Nanjo, K., Nagahama, H., (2000). Spatial distribution of aftershocks and the fractal structure of active fault systems. Pure and Applied Geophysics 157, 575e588, DOI: 10.1007/PL00001108.

[20] Turcotte, D. L., (1997). Fractal and Chaos in Geology and Geophysics, Cambridge university press. Cambridge.

[21] Berkowitz, B., and Hadad, A., (1997). Fractal and multifractal measures of natural and synthetic fracture networks, J. Geophys. Res., 102(B6), 12,205-12,218, DOI: 10.1029/97JB00304.

[22] Roy, A., Perfect, E., Dunne, W. M., and McKay, L. D. (2007). Fractal characterization of fracture networks: An improved box-counting technique, J. Geophys. Res., 112, B112201, DOI: 10.1029/2006JB004582.

[23] Kruhl, J.H. (2013). Fractal-geometry techniques in the quantification of complex rock structures: A special view on scaling regimes, inhomogeneity and anisotropy, Journal of Structural Geology, 46, pp. 2-21,

DOI: $10.1016 /$ j.jsg.2012.10.002.

[24] Pavičić, I., Dragičević, I., Vlahović, T., Grgasović, T. (2017). Fractal analysis of fracture systems in Upper Triassic Dolomites in Žumberak Mountain, Croatia. The Mining-Geology-Petroleum Engineering Bulletin, pp. 1-13, DOI: $10.1177 / \mathrm{rgn} .2017 .3 .1$

[25] Gonzalez, R.C. Woods, R.E. (2002). Digital Image Processing, 2nd ed., Prentice Hall, Upper Saddle River, NJ. 
[26] Hong, K. Han, E. and Kang, K. (2017). Determination of geological strength index of jointed rock mass based on image processing, Journal of Rock Mechanics and Geotechnical Engineering 9, pp. 702-708, DOI: $10.1016 / j . j r m g e .2017 .05 .001$.

[27] Hadjigeorgiou, J., Lemy, F., Cote, P., and Maldague, X. (2003). An evaluation of image analysis algorithms for constructing discontinuity trace maps. Rock Mechanics and Rock Engineering. 19(2), pp. 163 - 179, DOI: $10.1007 /$ s00603-002-0041-1.

[28] Kulatilake, P.H.S.W. Fiedler, R. Panda, B.B. (1997). Box fractal dimension as a measure of statistical homogeneity of jointed rock masses, Engineering Geology, 48, 3-4, pp. 217-229, DOI: 10.1016/S0013-7952(97)00045-8.

[29] Castleman KR. (2002). Digital image processing. Beijing, China: Tsinghua University Press.

[30] William KP. (2007). Digital image processing. 4th ed. John Wiley and Sons, Inc.

[31] Basirat, R., Goshtasbi, K., Ahmadi, M. (2019). Determination of the Fractal Dimension of the Fracture Network System Using Image Processing Technique. Fractal Fractional, 3, 17, DOI: 10.3390/fractalfract3020017. 